\title{
EFEITO DA MOAGEM DO SOLO NO TEOR DE FÓSFORO DISPONIVEL POR MEHLICH-1, RESINA EM ESFERAS E EM LÂMINA(1)
}

\author{
Marcelo Vieira Rolim ${ }^{(2)}$, Roberto Ferreira de Novais ${ }^{(3)}$, Flancer \\ Novais Nunes ${ }^{(4)}$ \& Víctor Hugo Alvarez V. ${ }^{(3)}$
}

\begin{abstract}
RESUMO
A moagem intensa de amostras de solo é necessária à utilização do método da resina de troca iônica, para a determinação do $P$ disponível, adotado em alguns laboratórios no Brasil. Como conseqüência dessa moagem, espera-se a extração de P da fração lábil do interior de agregados, aumentando o teor "disponível" e, por outro lado, aumentando a superficie específica da amostra, expondo sítios adicionais de adsorção e fixação de P. Objetivou-se com este trabalho conhecer o efeito de diferentes graus de moagem das amostras de solo sobre a eficiência de extração do Mehlich-1 e da resina na forma de esferas e de lâminas na determinação do $\mathbf{P}$ disponível em amostras de solo. Para isso, realizaram-se dois experimentos, um constituído por amostras superficiais de 14 solos não cultivados, nas quais foram determinados os teores de $\mathbf{P}$ pelos métodos: Mehlich-1, resina em esfera e resina em lâmina com amostras de solo submetidas a diferentes graus de moagem. No segundo experimento, utilizaram-se os mesmos métodos de extração em amostras de três solos, dos 14 solos utilizados no experimento anterior, adubados e cultivados com milho. Os resultados mostraram que a moagem das amostras de solo não aumentou a extração de $P$ pelo Mehlich-1 e resina em lâmina. Todavia, para a resina em esfera, a moagem causou aumento da extração de $P$, principalmente para os solos adubados e cultivados. $\mathrm{O} \mathrm{P}$ determinado pelos métodos correlacionouse bem com a resposta vegetal, embora essa correlação, quando as amostras foram moídas, tenha sido inferior.
\end{abstract}

Termos de indexação: análise de solo, tamanho de partícula, extração de fósforo, poder-tampão.

\footnotetext{
(1) Recebido para publicação em março de 2007 e aprovado em janeiro de 2008.

(2) Engenheiro-Agrônomo, MS em Fitotecnia, Universidade Federal de Viçosa - UFV. Avenida P.H. Rolfs s/n, CEP 36571-000 Viçosa (MG). E-mail: marcelo.rolim@mosaico.com

(3) Professor do Departamento de Solos, UFV. Bolsista do CNPq. E-mail: rfnovais@ufv.br; vhav@ufv.br

${ }^{(4)}$ Doutorando em Solos e Nutrição de Plantas pelo Departamento de Solos, UFV. E-mail: flancernovais@yahoo.com.br
} 


\title{
SUMMARY: EFFECT OF SOIL GRINDING ON AVAILABLE PHOSPHORUS CONTENT BY MEHLICH-1, BEAD AND MEMBRANE ION EXCHANGE RESINS
}

\begin{abstract}
The ion exchange resin method used in some laboratories in Brazil requires soil grinding for the determination of available $P$. As a consequence of grinding, the extraction of internal labile $P$ in aggregates is expected, increasing the concentration of available- $P$. On the other hand, finer grinding increases the exposure of soil particle surface, which creates additional sites for further $P$ adsorption. The aim of this study was to evaluate extraction efficiency available- $P$ by Mehlich-1, and anion exchange resin in beads and anion exchange resin in membrane form, in soil samples submitted to different grinding levels. Two experiments were carried out with three $P$ extraction methods. In the first experiment samples collected from 14 non-cultivated soils were used, ground at two levels. The second experiment was performed with three soils, selected among the 14 previously used soils, which were fertilized and cultivated with corn. Results showed that grinding of soil samples did not increase $P$ extraction by Mehlich-1 and membrane resin in noncultivated as well as in maize-cultivated soils. In the case of the bead resin extraction method, grinding led to an increased $P$ extraction, mainly in fertilized, cultivated soils. The available $P$ measured by the extraction methods and plant response were highly correlated, although the correlation was slightly lower for ground samples.
\end{abstract}

Index terms: soil analysis, particle size, phosphorus extraction, buffer capacity.

\section{INTRODUÇÃO}

Soluções extratoras podem ser utilizadas na determinação do $\mathrm{P}$ disponível dos solos, incluindo as compostas por ácidos, bases, sais, quelantes ou misturas desses e a resina de troca aniônica (Fixen \& Grove, 1990; Hosseinpur \& Ghanee, 2006). Extratores químicos, como o Mehlich-1, têm acesso a formas de $\mathrm{P}$ que variam entre o $\mathrm{P}$ em solução (fator intensidade) e o P lábil (fator capacidade), podendo, também, em certas situações, extrair parte do P não-lábil, sendo seus resultados influenciados por características do solo, principalmente, por aquelas ligadas ao fator capacidade ou poder-tampão (Novais \& Smyth, 1999). Para compensar o efeito do desgaste de extratores químicos, caracterizado pelo aumento do $\mathrm{pH}$ e adsorção de ânions de troca ( $\mathrm{SO}_{4}{ }^{2-}$ e $\mathrm{Cl}^{-}$no caso do Mehlich-1), por características do solo relacionadas com o fator capacidade, torna-se necessária a inclusão de medida deste fator, como o teor de argila (Gunary \& Sutton, 1967) e, mais recentemente, o P-remanescente (Alvarez V. et al., 2000), na interpretação dos resultados destes métodos (CFSEMG, 1999). Todavia, extratores como o Mehlich-1, amplamente difundido no Brasil, têm recebido várias críticas em razão da solubilização de formas não-lábeis de $\mathrm{P}$ como o P-Ca, superestimando os valores de $\mathrm{P}$ disponível em solos adubados com fosfatos naturais e naqueles que pela gênese apresentam teor elevado de P-Ca. No entanto, o método ainda é bastante utilizado, pois, além de sua praticidade comprovada, de modo geral, os solos do País são ácidos, muito intemperizados e pobres em P-Ca.

O método da resina de troca de íons é indicado como alternativa para os problemas encontrados com a utilização do Mehlich-1, sendo apontado por muitos pesquisadores como eficiente método na avaliação do
P disponível (Fixen \& Grove, 1990). Um aspecto favorável ao método da resina é que este é menos influenciado pelas características dos solos que o Mehlich-1. Outras características favoráveis ao método é que pode ser usado também em solos alcalinos, não superestimando a disponibilidade de $\mathrm{P}$ em solos que receberam fosfato natural como os extratores ácidos e por simular mais eficientemente o comportamento das raízes das plantas (Silva \& Raij, 1999). Uma das críticas à resina refere-se à pouca praticidade do método, dificultando seu uso em larga escala (Moreira \& Malavolta, 2001).

Para melhorar sua eficiência de extração, algumas alterações foram adotadas, embora a moagem das amostras ainda seja necessária para separar a resina do solo (Sibbesen, 1978; Myers et al., 2005). Além de reduzir a operacionalidade do método, a moagem das amostras pode alterar características físicas e químicas do solo, alterando a quantidade de $\mathrm{P}$ que pode ser extraída pela resina (Zunino et al., 1972) e pelo Bray-2 (Houba et al., 1993). Outra limitação à utilização da resina em forma de esfera é a necessidade de seu acondicionamento em saquinhos de tela de poliéster, que, além de reduzir sua praticidade, restringe o equilíbrio solo-água-resina (Lee \& Doolittle, 2002).

$\mathrm{Na}$ tentativa de contornar os inconvenientes da resina em esferas, atualmente, a resina na forma de lâmina vem sendo utilizada na determinação do P disponível (Fernandes \& Warren, 1995; Bissani et al., 2002). A resina em forma de lâmina aumenta a praticidade do método de extração de $\mathrm{P}$ em laboratórios de rotina de análise de solo, pois facilita a sua separação do solo, evitando os inconvenientes do método da resina em forma de esferas, como a moagem das amostras de solo e necessidade de seu acondicionamento em saquinhos de poliéster. Outra característica positiva 
da resina em lâmina é o seu baixo custo, uma vez que pode ser reutilizada por até 500 vezes sem perder seu poder de extração em solos com diferentes capacidades de adsorção de $\mathrm{P}$ e teor de Ca trocável (Saggar et al., 1990).

Pela sua praticidade e habilidade de ser utilizada diretamente no solo, a resina em lâmina torna-se um método promissor para laboratórios de análise de rotina, provavelmente apresentando vantagens em relação à utilização de resina em esferas em alguns laboratórios de rotina do País.

Assim, o presente trabalho objetivou avaliar o efeito da moagem das amostras de solo na eficiência de extração da resina em lâmina em solos com diferentes características químicas e físicas, comparando-a com método de Mehlich-1 e resina em esferas.

\section{MATERIAL E MÉTODOS}

Foram utilizadas amostras de terra da camada de 0-20 cm de 14 solos, não cultivados, com ampla variação textural (teor de argila variando de 12,0 a $84,2 \%$ ). Os solos pertencem às classes: Latossolo Amarelo distrófico (LAd), Latossolo Bruno distrófico $(\mathrm{LBd})$, Latossolo Vermelho ácrico $\left(\mathrm{LV}_{\mathrm{W}}\right)$, Latossolo Vermelho distrofico típico $\left(\mathrm{LV}_{\mathrm{d}}\right)$ e Neossolo Quartzarénico órtico $\left(\mathrm{RQ}_{\mathrm{O}}\right)$. As amostras foram destorroadas e passadas em peneira de $4,0 \mathrm{~mm}$ de abertura e secas ao ar. Amostras passadas em peneira com malha de $2 \mathrm{~mm}$ foram utilizadas para a caracterização química, P-remanescente (P-rem) (Alvarez V. et al., 2000), capacidade máxima de adsorção de $\mathrm{P}$ (CMAP) pela isoterma de Langmuir (Alvarez $\mathrm{V}$. \& Fonseca, 1990); $\mathrm{pH}, \mathrm{Al}^{3+}, \mathrm{Ca}^{2+}, \mathrm{Mg}^{2+}, \mathrm{K}^{+}, \mathrm{H}+\mathrm{Al} \mathrm{e}$ $\mathrm{C}$ de compostos orgânicos (CO) (Defelipo \& Ribeiro, 1997) e granulométrica (Ruiz, 2005) (Quadro 1).

Dois ensaios foram realizados e analisados separadamente. No primeiro, foram utilizadas as amostras de 14 solos e o ensaio foi feito em laboratório, enquanto, no segundo, apenas três dos 14 solos (escolhidos com base nos valores de CMAP e teor de argila) foram utilizados após serem fertilizados e submetidos a um cultivo em casa de vegetação.

O $\mathrm{P}$ disponível das amostras foi extraído pelos métodos: Mehlich-1, utilizando amostras de terra fina seca ao ar (TFSA) (MP); Mehlich-1, utilizando amostras de solo moídas em almofariz até passarem totalmente em peneira de $0,25 \mathrm{~mm}$ de abertura (MM); resina em esfera (diâmetro $=0,25 \mathrm{~mm}$ ), utilizando TFSA (REP); resina em esfera em saquinho de tela de poliéster, utilizando TFSA (RESP); resina em esfera em saquinho de tela de poliéster, utilizando solo moído (RESM); resina em lâmina, utilizando TFSA (RLP); resina em lâmina, utilizando amostras de solo moído (RLM); resina em lâmina, utilizando TFSA, moída pela agitação com bolas de vidro em $25 \mathrm{~mL}$ de água por 15 min (RLB). Para os métodos de extração com resina em esferas ou lâmina, agitou-se a resina com $2,5 \mathrm{~cm}^{3}$ de solo na presença de $25 \mathrm{~mL}$ de água destilada por $2 \mathrm{~h}$, a $150 \mathrm{rpm}$.

Foram utilizadas resinas de troca aniônica em forma de lâmina (modelo AR.103.QPD, Ionics, Inc., USA), cortadas em tiras de 2 x $5 \mathrm{~cm}$ e em forma de esferas (Amberlite, modelo IRA - 400). As resinas foram pré-condicionadas e saturadas com solução de $\mathrm{NaHCO}_{3} 1 \mathrm{~mol} \mathrm{~L}^{-1}$ (Raij et al., 1987). O P adsorvido

Quadro 1. Características químicas e físicas das amostras dos solos

\begin{tabular}{|c|c|c|c|c|c|c|c|c|c|c|c|}
\hline Solo & P rem ${ }^{(1)}$ & $\operatorname{CMAP}^{(2)}$ & $\mathbf{p H}$ & $\mathrm{Al}^{3+}$ & $\mathrm{Ca}^{2+}$ & $\mathrm{Mg}^{2+}$ & $\mathbf{K}^{+}$ & $\mathbf{H}+\mathbf{A l}$ & $\mathrm{CO}$ & Argila & Areia \\
\hline & $\mathrm{mg} \mathrm{L}^{-1}$ & \multicolumn{2}{|l|}{$\mathrm{mg} \mathrm{dm}^{-3}$} & \multicolumn{5}{|c|}{$-\mathrm{cmol}_{\mathrm{c}} \mathrm{dm}^{-3}$} & dag kg-1 & — $\%$ & 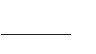 \\
\hline $\mathrm{LA}_{d}-1$ & 29,9 & 453 & 4,40 & 1,51 & 0,19 & 0,10 & 0,03 & 3,64 & 0,25 & 35,0 & 63,1 \\
\hline $\mathrm{LA}_{d}-2$ & 46,1 & 299 & 5,03 & 1,29 & 1,09 & 0,23 & 0,03 & 2,94 & 0,70 & 21,0 & 69,0 \\
\hline $\mathrm{LB}_{\mathrm{d}}$ & 15,0 & 818 & 4,71 & 0,90 & 0,92 & 0,22 & 0,09 & 7,19 & 2,22 & 60,4 & 31,2 \\
\hline $\mathrm{LV}_{\mathrm{w}}$ & 3,2 & 1.757 & 4,38 & 1,74 & 0,94 & 0,15 & 0,08 & 12,84 & 2,13 & 72,0 & 15,0 \\
\hline $\mathrm{LV}_{\mathrm{d}-1}$ & 21,1 & 659 & 4,97 & 1,41 & 0,24 & 0,42 & 0,12 & 5,22 & 0,82 & 23,0 & 75,0 \\
\hline$L V_{d}-2$ & 38,1 & 335 & 4,64 & 0,75 & $\mathrm{ND}^{3}$ & 0,04 & 0,05 & 3,17 & 0,53 & 12,0 & 86,1 \\
\hline$L V_{d}-3$ & 3,4 & 1.673 & 5,34 & 0,90 & 0,08 & 0,09 & 0,08 & 7,89 & 2,28 & 67,0 & 17,0 \\
\hline $\mathrm{LV}_{\mathrm{d}}-4$ & 4,8 & 1.887 & 5,00 & 1,08 & $\mathrm{ND}$ & 0,06 & 0,08 & 8,28 & 2,13 & 60,0 & 21,0 \\
\hline$L_{d}-5$ & 4,6 & 1.728 & 4,70 & 0,89 & 0,10 & 0,13 & 0,01 & 7,89 & 2,11 & 68,0 & 10,9 \\
\hline $\mathrm{LV}_{\mathrm{d}}-6$ & 1,8 & 1.936 & 4,64 & 0,52 & 0,19 & 0,16 & 0,19 & 8,66 & 2,85 & 54,0 & 22,0 \\
\hline $\mathrm{LV}_{\mathrm{d}}-7$ & 29,9 & 434 & 4,99 & 0,75 & $\mathrm{ND}$ & 0,03 & 0,03 & 2,48 & 0,30 & 16,0 & 81,0 \\
\hline$L V_{d}-8$ & 12,0 & 1.001 & 4,79 & 0,59 & 0,61 & 0,30 & 0,06 & 8,70 & 2,38 & 84,2 & 14,3 \\
\hline $\mathrm{RQ}_{\mathrm{o}-1}$ & 37,1 & 397 & 5,05 & 1,13 & 0,18 & 0,17 & 0,13 & 4,64 & 0,51 & 12,0 & 87,0 \\
\hline $\mathrm{RQ}_{\mathrm{o}-2}$ & 40,1 & 33 & 5,00 & 0,61 & 0,59 & ND & 0,70 & 6,29 & 0,82 & 12,6 & 82,9 \\
\hline
\end{tabular}

(1) Fósforo remanescente. ${ }^{(2)}$ Capacidade máxima de adsorsão de fósforo. ${ }^{(3)} \mathrm{ND}$ : não detectado; pH em água - relação (1:2,5); Al ${ }^{3+}$, $\mathrm{Ca}^{2+}$ e $\mathrm{Mg}^{2+}$ - Extrator $\mathrm{KCl} 1 \mathrm{~mol} \mathrm{~L}{ }^{-1} ; \mathrm{K}^{+}$- extrator Mehlich-1; CO - método de Walkley \& Black; Argila - método da pipeta; areia - peneiramento. 
às resinas foi extraído com $20 \mathrm{~mL}$ de $\mathrm{HCl} 0,5 \mathrm{~mol} \mathrm{~L}^{-1}$, por $2 \mathrm{~h}$ de agitação, a $150 \mathrm{rpm}$. Em todos os extratos, as concentrações de $\mathrm{P}$ foram dosadas por espectrometria de absorção molecular, utilizando ácido ascórbico como redutor (Murphy \& Riley, 1962).

No primeiro ensaio, os tratamentos constituíram um fatorial 14 x 8, pela combinação dos 14 solos com os oito métodos de extração de $\mathrm{P}$.

No ensaio com solos cultivados, foram utilizados os solos $\mathrm{LB}_{\mathrm{d}}, \mathrm{LV}_{\mathrm{d}}-8$ e RQ $\mathrm{O}^{-2}$ (Quadro 1). As unidades experimentais, constituídas por vasos com capacidade de $2 \mathrm{dm}^{3}$, preenchidos com 1,8 $\mathrm{dm}^{3}$ de solo, receberam doses de corretivo com base no critério de $\mathrm{Al} \mathrm{e} \mathrm{Ca}+\mathrm{Mg}$ trocáveis. Cada unidade experimental recebeu mistura de $\mathrm{CaCO}_{3}$ e $\mathrm{MgCO}_{3}$, na relação molar de 4:1, e água deionizada até à capacidade de campo; depois foram incubadas por 30 dias em sacos plásticos.

Após a incubação, o solo foi seco à sombra, destorroado e passado por peneira de $4 \mathrm{~mm}$. Aplicaram-se, então, seis doses de $\mathrm{P}$, variáveis entre os solos, definidas de acordo com seus teores de argila (Quadro 2). Foram utilizadas combinações variáveis de $\mathrm{KH}_{2} \mathrm{PO}_{4}$, $\mathrm{NH}_{4} \mathrm{H}_{2} \mathrm{PO}_{4}$ e $\mathrm{Ca}\left(\mathrm{H}_{2} \mathrm{PO}_{4}\right)_{2}$, com posterior balanceamento dos nutrientes. Para isso, a fonte de $\mathrm{P}$ utilizada na dose de $100 \mathrm{mg} \mathrm{dm}^{-3}$ de $\mathrm{P}$ foi o $\mathrm{KH}_{2} \mathrm{PO}_{4}$, completando-

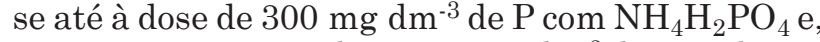
para atingir a maior dose, $500 \mathrm{mg} \mathrm{dm}^{-3} \mathrm{de} \mathrm{P}$, utilizouse $\mathrm{Ca}\left(\mathrm{H}_{2} \mathrm{PO}_{4}\right)_{2}$. $\mathrm{O} \mathrm{K}$ foi balanceado de forma que cada unidade experimental recebesse $125 \mathrm{mg} \mathrm{dm}^{-3}$ de K como $\mathrm{KCl}$ ou $\mathrm{KH}_{2} \mathrm{PO}_{4}$. Da mesma forma, adicionouse $\mathrm{NH}_{4} \mathrm{NO}_{3}$ para que todos os vasos recebessem $90 \mathrm{mg} \mathrm{dm}^{-3}$ de N. O solo de cada vaso foi umedecido até à capacidade de campo, determinada pelo método da centrífuga (Ruiz et al., 2003), e incubado, novamente, por 25 dias. Após esse período, cada vaso recebeu seis sementes de milho (Agroceres AG 1051), em seguida, foram aplicados via solução, nas doses $\left(\mathrm{mg} \mathrm{dm} \mathrm{m}^{-3}\right)$, os seguintes nutrientes: 2 de B, $2 \mathrm{de} \mathrm{Cu}, 5$ de $\mathrm{Zn}$, e 0,3 de $\mathrm{Mo}$, utilizando as fontes: $\mathrm{H}_{3} \mathrm{BO}_{3}$, $\mathrm{CuSO}_{4} \cdot 5 \mathrm{H}_{2} \mathrm{O}, \mathrm{ZnSO}_{4} \cdot 7 \mathrm{H}_{2} \mathrm{O}$ e $\left(\mathrm{NH}_{4}\right)_{6} \mathrm{Mo}_{7} \mathrm{O}_{24} \cdot 4 \mathrm{H}_{2} \mathrm{O}$, respectivamente. Cinco dias após a emergência, fezse um desbaste, deixando quatro plantas por vaso. Aos 15 e 30 dias do plantio, aplicaram-se $61 \mathrm{mg} \mathrm{dm}^{-3}$ de $\mathrm{N}$ na forma de uréia. Aos 39 dias, as plantas foram cortadas rente ao solo, acondicionadas em sacos de papel e secas em estufa a $70^{\circ} \mathrm{C}$ por $72 \mathrm{~h}$.

\section{Quadro 2. Doses de fósforo aplicadas a três solos} para cultivo de milho

\begin{tabular}{|c|c|c|c|c|c|c|}
\hline \multirow[t]{2}{*}{ Solo } & \multicolumn{6}{|c|}{ Dose de P } \\
\hline & \multicolumn{6}{|c|}{$-\mathrm{mgdm}^{-3}$} \\
\hline $\mathrm{LBd}$ & 0 & 40 & 80 & 160 & 240 & 400 \\
\hline $\mathrm{LV}_{\mathrm{d}}-8$ & 0 & 50 & 100 & 200 & 300 & 500 \\
\hline RQo-2 & 0 & 20 & 40 & 80 & 120 & 200 \\
\hline
\end{tabular}

O material vegetal foi seco e moído e submetido à digestão nítricoperclórica, relação em base volumétrica 4:1 e, no extrato, determinou-se o teor de $\mathrm{P}$. O solo de cada vaso foi seco, passado em peneira de $2,0 \mathrm{~mm}$ de abertura, descartando-se as raízes e, em seguida, homogeneizado. Nas amostras de cada vaso, foi determinado o "P disponível", utilizando os métodos descritos no experimento anterior.

O segundo ensaio foi constituído pelo fatorial $3 \times 6 \times 8$, formado pela combinação dos três solos, com seis doses de $\mathrm{P}$ e oito diferentes métodos de extração de P (144 tratamentos), em delineamento de blocos ao acaso com três repetições.

Análises de correlação foram utilizadas para avaliar a variação concomitante entre os métodos de extração. Os solos foram divididos em grupos, para a melhor avaliação dos extratores, de acordo com o P-rem: solos com baixo valor (menor que $15 \mathrm{mg} \mathrm{L}^{-1}$ ) e solos com alto valor (igual ou superior a $15 \mathrm{mg} \mathrm{L}^{-1}$ ) (Novais R.F., comunicação pessoal).

Foi feita análise de variância para a produção de matéria seca da parte aérea, para o teor de $\mathrm{P}$ na matéria seca e para o P extraído do solo, bem como feita a correlação linear simples dos teores de $\mathrm{P}$ extraídos pelos oito métodos e a produção de matéria seca, teor e conteúdo de $\mathrm{P}$ das plantas de milho. Os métodos de extração de $\mathrm{P}$ foram avaliados estatisticamente por meio de contrastes ortogonais, aceitando significância até $5 \%$.

\section{RESULTADOS E DISCUSSÃO}

\section{Efeito da moagem das amostras nos solos não adubados e não cultivados}

Os teores de $\mathrm{P}$ disponível pelos métodos Mehlich-1 (MP) e resina em lâmina (RLP) foram, em média, 2,8 vezes menores que os teores de $\mathrm{P}$ extraído pelos métodos resina em esfera (REP e RESP) (Quadro 3). A moagem das amostras não teve efeito significativo para o P extraído pelo Mehlich-1. Entretanto, houve aumento médio de $29 \%$ no $\mathrm{P}$ extraído, com grande incremento no solo $\mathrm{RQ}_{\mathrm{O}}-1$ e pequena diminuição no $\mathrm{LV}_{\mathrm{d}} 5$ (Quadros 3 e 4 C3). Esse efeito não-significativo deve-se, provavelmente, ao fato de a moagem aumentar o desgaste do extrator pelo solo, compensando o aumento de capacidade de solubilização de novas formas expostas de P. Em outros solos, a moagem das amostras aumentou o $\mathrm{P}$ extraído pelo Bray-2, em razão do aumento de superfícies expostas, com mais P disponível (Yoshida, 1992; Houba et al., 1993).

Para a resina em esfera acondicionada em saquinho, a moagem aumentou significativamente o $\mathrm{P}$ extraído (Quadro 3 e $4 \overline{C 4}$ ). Essa diferença significativa para a resina deve-se, provavelmente, ao fato de o extrator não sofrer desgaste pelos componentes do fator 
Quadro 3. Teores de P extraído pelo Mehlich-1 (MP), Mehlich-1 com solo moído (MM), resina em esfera (REP), resina em esfera em saquinho (RESP), resina em esfera em saquinho com solo moído (RESM), resina em lâmina (RLP), resina em lâmina com solo moído (RLM) e resina em lâmina com solo moído por bola de vidro (RLB) em amostras dos solos não cultivados

\begin{tabular}{|c|c|c|c|c|c|c|c|c|}
\hline Solo & MP & MM & REP & RESP & RESM & RLP & RLM & RLB \\
\hline & \multicolumn{8}{|c|}{$\mathrm{mg} \mathrm{dm}^{-3}$} \\
\hline $\mathrm{LA}_{d}-1$ & 0,7 & 0,9 & 4,1 & 2,2 & 2,9 & 0,9 & 0,6 & 0,3 \\
\hline $\mathrm{LA}_{d}-2$ & 1,5 & 1,5 & 4,3 & 2,9 & 3,9 & 1,6 & 1,3 & 0,9 \\
\hline $\mathrm{LB}_{\mathrm{d}}$ & 1,3 & 1,7 & 3,6 & 2,9 & 4,4 & 1,2 & 0,9 & 0,6 \\
\hline $\mathrm{LV}_{\mathrm{W}}$ & 2,0 & 2,1 & 6,0 & 5,3 & 5,2 & 1,7 & 1,4 & 1,3 \\
\hline$L V_{d}-1$ & 2,5 & 3,0 & 6,2 & 4,4 & 4,6 & 2,5 & 2,1 & 1,9 \\
\hline$L V_{d}-2$ & 1,6 & 1,8 & 5,1 & 2,7 & 3,5 & 2,1 & 1,2 & 1,1 \\
\hline$L V_{d}-3$ & 1,0 & 1,3 & 5,0 & 3,9 & 3,9 & 2,0 & 1,2 & 0,9 \\
\hline $\mathrm{LV}_{\mathrm{d}}-4$ & 0,8 & 0,9 & 5,8 & 4,2 & 4,8 & 1,8 & 1,6 & 1,4 \\
\hline$L V_{d}-5$ & 1,1 & 1,0 & 5,0 & 3,8 & 4,2 & 1,5 & 1,5 & 0,9 \\
\hline $\mathrm{LV}_{\mathrm{d}}-6$ & 0,8 & 0,9 & 3,8 & 3,3 & 4,0 & 1,6 & 0,9 & 0,6 \\
\hline $\mathrm{LV}_{\mathrm{d}}-7$ & 0,7 & 0,9 & 3,9 & 2,0 & 3,2 & 0,9 & 0,8 & 0,3 \\
\hline$L V_{d}-8$ & 1,5 & 2,4 & 5,3 & 3,5 & 5,0 & 1,4 & 1,2 & 0,8 \\
\hline RQo-1 & 2,6 & 4,7 & 7,0 & 3,7 & 4,0 & 2,7 & 2,4 & 2,1 \\
\hline $\mathrm{RQ}-2$ & 1,1 & 1,8 & 3,1 & 2,4 & 6,9 & 0,8 & 2,9 & 0,4 \\
\hline Média & 1,37 & 1,78 & 4,87 & 3,37 & 4,32 & 1,62 & 1,43 & 0,96 \\
\hline
\end{tabular}

Quadro 4. Contrastes médios ( $\bar{C})$ dos teores de P extraídos de 14 solos pelo Mehlich-1 (MP), Mehlich-1 com solo moído (MM), resina em esfera (REP), resina em esfera em saquinho (RESP), resina em esfera em saquinho com solo moído (RESM), resina em lâmina (RLP), resina em lâmina com solo moído (RLM) e resina em lâmina com solo moído por bola de vidro (RLB)

\begin{tabular}{lllllll}
\hline \multicolumn{8}{c}{ Contraste } \\
\hline$\overline{\mathrm{C} 1}$ & $\overline{\mathrm{C} 2}$ & $\overline{\mathrm{C} 3}$ & $\overline{\mathrm{C} 4}$ & $\overline{\mathrm{C} 5}$ & $\overline{\mathrm{C} 6}$ & $\overline{\mathrm{C} 7}$ \\
\hline
\end{tabular}

\begin{tabular}{|c|c|c|c|c|c|c|}
\hline $4,39^{* *}$ & $-2,32^{* *}$ & $-0,41^{\mathrm{ns}}$ & $0,95^{*}$ & $-0,19^{\mathrm{ns}}$ & $-1,75^{* *}$ & $-0,47^{*}$ \\
\hline
\end{tabular}

ns, ${ }^{* *} \mathrm{e}^{*}$ : não-significativo e significativos a 5 e $1 \%$ pelo teste $F$. $\overline{C 1}=-2 \mathrm{MP}-2 \mathrm{MM}+\mathrm{RESP}+\mathrm{RESM}+\mathrm{RLP}+\mathrm{RLM} ; \overline{C 2}=$ -RESP - RESM + RLP + RLM; $\overline{C 3}=-\mathrm{MP}+\mathrm{MM} ; \overline{C 4}=-\mathrm{RESP}$ $+\mathrm{RESM} ; \overline{C 5}=-\mathrm{RLP}+\mathrm{RLM} ; \overline{C 6}=-\mathrm{RESP}+\mathrm{RLP} ; \overline{C 7}=-\mathrm{RLM}$ + RLB.

capacidade do solo, como ocorre com o Mehlich-1, assim a resina não perde seu poder de extração com a moagem. O aumento do $\mathrm{P}$ extraído pela resina em esfera é, também, decorrência do aumento de superfícies com mais $\mathrm{P}$ lábil devido à moagem (Yoshida, 1992; Houba et al., 1993). Comparando a resina em esferas acondicionadas em saquinho com a resina em esferas "livres", como indicada por Raij et al. (1987), observa-se menor teor de P disponível extraído pela resina em saquinho, principalmente para as amostras que não foram submetidas à moagem (Quadro 3), dado o menor contato das partículas de solo com a resina, reduzindo sua capacidade extratora (Lee \& Doolittle, 2002).

Os teores de $\mathrm{P}$ extraídos pela resina em lâmina (RLP e RLM) foram significativamente menores que os extraídos pela resina em esferas (REP e RESM) (Quadro $4 \overline{C 2}$ ). Esta diferença, em relação à resina em esferas, parece ser causada pela menor superfície extratora da resina em lâmina, que não permitiu que esta acessasse formas de $\mathrm{P}$ que a moagem tornou extraíveis. Essa menor capacidade extratora deve-se, também, ao fato de a matriz inerte da lâmina manter estável seu formato, o que não contribui com maior contato da resina com o solo. Nesse contexto, Fernandes \& Warren (1995) avaliaram a capacidade extratora da resina aniônica em forma de esferas e de lâmina e constataram que a resina em esferas extraiu 1,5 vez mais $\mathrm{P}$ que a resina em lâmina, para solos que receberam, ou, não, $\mathrm{P}$.

Myes et al. (2005) avaliaram a eficiência e a praticidade de diferentes extratores de $\mathrm{P}$, dentre os mais utilizados nos EUA, e constataram que a capacidade de extração da resina em lâmina foi similar à da resina em esfera somente quando se utilizaram três lâminas, que somados às áreas, apresentaram, $51,8 \mathrm{~cm}^{2}$, evidenciando que o P extraído pela resina é dependente de sua superficie.

Os teores de $\mathrm{P}$ pela resina em lâmina correlacionaram-se com o teor de $\mathrm{P}$ extraído pelo Mehlich-1, mesmo com a moagem das amostras de solo, embora a correlação entre os métodos diminua com a moagem. Todavia, a moagem não alterou o comportamento da 
resina em lâmina em relação ao Mehlich-1. Esse resultado indica menor capacidade extratora da resina em lâmina, comparada a resina em esferas, que não foi capaz de extrair formas de $\mathrm{P}$ que estariam, inicialmente, não-extraíveis e que a moagem teria exposto. O único método que apresentou correlação com o RESM, indicando modo de ação semelhante, foi a resina em lâmina com a amostra moída (RLM) (Quadro 5). O Mehlich-1 com a amostra de solo moída (MM) não se correlacionou com o método da resina em esferas em saquinho (RESP) e com o RESM, provavelmente por causa da diferente forma de ação desses extratores. Porém, esse não é o caso da resina em esfera (RESM) e em lâmina (RLM), evidenciando o comportamento semelhante da resina, independentemente de sua forma, em relação à moagem das amostras.

Ao analisar apenas os solos com menor fator capacidade, valor de $\mathrm{P}$-rem maior que $15 \mathrm{mg} \mathrm{L}^{-1}$, onde o desgaste de extrator Mehlich-1 é menor, a correlação entre P extraído pelo MP, pela REP e RLP melhora (Quadro 5). Nessa condição, os resultados dos métodos que usam Mehlich-1 (MP e MM), de forma geral, correlacionam-se melhor com os métodos que utilizam resina (REP, RESP, RLP, RLM e RLB). Ao analisar apenas solos com menor teor de argila, Silva \& Raij (1996) também encontraram maior correlação entre os resultados da resina e do Mehlich-1, além de melhor resposta do crescimento de plantas.

Os métodos de análise de resina com amostra de solo moído (RESM e RLM) não se correlacionaram, de modo geral, com os outros métodos quando os solos de menor fator capacidade foram considerados separadamente (Quadro 5). Contudo, para os solos com maior fator capacidade, os métodos de resina que receberam moagem tiveram seus resultados mais bem correlacionados com os dos outros métodos. Uma possível explicação para as melhores correlações com os métodos que receberam moagem nos solos com alto fator capacidade é que nesses solos a moagem aumenta o teor de $\mathrm{P}$ extraído, o que resulta em maior discriminação de valores, possibilitando melhor detecção de diferenças significativas.

Quadro 5. Coeficiente de correlação linear simples entre os valores médios de P extraído pelo Mehlich-1 (MP), Mehlich-1 com solo moído (MM), resina em esferas (REP), resina em esferas em saquinho (RESP), resina em esferas em saquinho com solo moído (RESM), resina em lâmina (RLP), resina em lâmina com solo moído (RLM) e resina em lâmina com solo moído por bola de vidro (RLB) em amostras dos solos não cultivados

\begin{tabular}{|c|c|c|c|c|c|c|c|}
\hline & MP & MM & REP & RESP & RESM & RLP & RLM \\
\hline & \multicolumn{7}{|c|}{ Para todos os solos } \\
\hline MM & $0,91 * * *$ & & & & & & \\
\hline $\mathrm{RE}$ & $0,72 * *$ & $0,66 * *$ & & & & & \\
\hline RES & $0,51^{*}$ & $0,32^{\mathrm{ns}}$ & $0,74^{* *}$ & & & & \\
\hline RESM & $0,18^{\mathrm{ns}}$ & $0,19^{\mathrm{ns}}$ & $-0,04^{\mathrm{ns}}$ & $0,29^{\mathrm{ns}}$ & & & \\
\hline RL & $0,76 * * *$ & $0,68 * *$ & $0,84 * * *$ & $0,61 * *$ & $-0,12^{\mathrm{ns}}$ & & \\
\hline RLM & $0,53^{*}$ & $0,59 *$ & $0,32^{\mathrm{ns}}$ & $0,24^{\mathrm{ns}}$ & $0,70 * *$ & $0,35^{\mathrm{ns}}$ & \\
\hline \multirow[t]{2}{*}{ RLB } & $0,87 * * *$ & $0,77 * * *$ & $0,91 * * *$ & $0,71 * *$ & $0,05^{\mathrm{ns}}$ & $0,93 * * *$ & $0,47^{*}$ \\
\hline & \multicolumn{7}{|c|}{ Para solos com baixo P-remanescente $e^{(1)}$} \\
\hline MM & $0,86^{* *}$ & & & & & & \\
\hline $\mathrm{RE}$ & $0,41^{\mathrm{ns}}$ & $0,22^{\mathrm{ns}}$ & & & & & \\
\hline RES & $0,53^{\mathrm{ns}}$ & $0,16^{\mathrm{ns}}$ & $0,84^{* *}$ & & & & \\
\hline RESM & $0,73^{*}$ & $0,67^{\mathrm{ns}}$ & $0,65^{\mathrm{ns}}$ & $0,52^{\mathrm{ns}}$ & & & \\
\hline $\mathrm{RL}$ & $-0,16^{\mathrm{ns}}$ & $-0,30^{\mathrm{ns}}$ & $0,55^{\mathrm{ns}}$ & $0,60^{\mathrm{ns}}$ & $-0,14^{\mathrm{ns}}$ & & \\
\hline RLM & $0,03^{\mathrm{ns}}$ & $-0,18^{\text {ns }}$ & $0,85^{* *}$ & $0,62^{\mathrm{ns}}$ & $0,43^{\mathrm{ns}}$ & $0,38^{\mathrm{ns}}$ & \\
\hline \multirow[t]{2}{*}{ RLB } & $0,27^{\mathrm{ns}}$ & $-0,01^{\mathrm{ns}}$ & $0,93^{* *}$ & $0,87 * *$ & $0,59^{\mathrm{ns}}$ & $0,59^{\mathrm{ns}}$ & $0,85^{* *}$ \\
\hline & \multicolumn{7}{|c|}{ Para solos com alto P-remanescente ${ }^{(2)}$} \\
\hline MM & $0,92 * *$ & & & & & & \\
\hline $\mathrm{RE}$ & $0,91 * *$ & $0,87 * *$ & & & & & \\
\hline RES & $0,95 * * *$ & $0,80 * *$ & $0,84 * *$ & & & & \\
\hline RESM & $0,15^{\mathrm{ns}}$ & $0,17^{\mathrm{ns}}$ & $-0,23^{\mathrm{ns}}$ & $0,15^{\mathrm{ns}}$ & & & \\
\hline $\mathrm{RL}$ & $0,96 * * *$ & $0,85^{* *}$ & $0,88^{* *}$ & $0,96 * * *$ & $-0,10^{\mathrm{ns}}$ & & \\
\hline RLM & $0,58^{\mathrm{ns}}$ & $0,66^{\mathrm{ns}}$ & $0,53^{\mathrm{ns}}$ & $0,26^{\mathrm{ns}}$ & $0,87^{* *}$ & $0,34^{\mathrm{ns}}$ & \\
\hline RLB & $0,99 * * *$ & $0,92^{* *}$ & $0,93^{* *}$ & $0,96 * * *$ & $-0,01^{\mathrm{ns}}$ & $0,98 * * *$ & $0,46^{\mathrm{ns}}$ \\
\hline
\end{tabular}

(1) $\mathrm{P}$ remanescente baixo: menor que $15 \mathrm{mg} \mathrm{L}^{-1} .{ }^{(2)} \mathrm{P}$ remanescente alto: superior ou igual a $15 \mathrm{mg} \mathrm{L}^{-1}$. ${ }^{\mathrm{ns}}$, *, ${ }^{* *}$ e $* * *$ Nãosignificativo e significativo pelo teste $\mathrm{F}$ a 5,1 e $0,1 \%$. 
Efeito da moagem das amostras nos solos adubados e cultivados

A moagem das amostras aumentou significativamente a capacidade de extração do extrator Mehlich-1, possivelmente em razão de parte do $\mathrm{P}$ adicionado ser adsorvido por difusão para o interior dos agregados do solo, disponibilizado com a quebra desses agregados (Quadro 6). Concordando com essa afirmação, Wang et al. (2001) cultivaram plantas de alface e soja, utilizando, como substrato, agregados de solo oxídico de diferentes tamanhos; esses autores constataram aumento na absorção de $\mathrm{P}$ pelas plantas com o aumento do tamanho dos agregados, em decorrência da menor superfície de adsorção de $\mathrm{P}$ pelos agregados de maior tamanho. Dessa forma, nos solos cultivados, esse elemento deve-se encontrar em formas menos estáveis ou ainda não-oclusas, sendo mais facilmente extraíveis, o que justifica a maior extração do Mehlich-1 com moagem.

Em média, a resina em esferas extraiu teores semelhantes de P nos solos cultivados, independentemente do modo de preparo das amostras. A resina em lâmina, porém, apresentou menores valores de P extraído com a moagem das amostras de solo, principalmente com a moagem por bolas de vidro. A redução do $\mathrm{P}$ extraído com a moagem também foi observada em outros trabalhos (Houba et al., 1993; Takahashi, 1996) e pode estar ligada à reagregação das partículas do solo. Esse resultado é aplicável principalmente para solos ou materiais pouco cristalinizados, não sendo estritamente verdadeiro para os solos utilizados no trabalho que não sofreram moagem tão intensa. Explicação para a redução de extração em algumas amostras pode ser encontrada no trabalho de Yoshida (1992) que utilizou ampla gama de solos, incluindo solos oxídicos. Esse autor concluiu que, em solos ricos em $\mathrm{P}$, como é o caso mais freqüente de solos adubados e cultivados, a moagem prolongada pode levar à formação de compostos pouco solúveis de $\mathrm{P}$ e novas ligações entre a fase sólida do solo e o $\mathrm{P}$, reduzindo sua labilidade e a possibilidade de sua extração.

Diferentemente do observado para os solos não adubados, para os solos adubados e cultivados os métodos de extração correlacionaram-se, significativamente, entre si (coeficiente de correlação > 0,9; ***, dados não mostrados). Com incremento das doses de $\mathrm{P}$, os métodos extraíram quantidades maiores de $\mathrm{P}$, resultando em coeficientes de correlação mais altos do que os obtidos para os solos não cultivados. Considerando o grande efeito da adição de $\mathrm{P}$, o preparo das amostras de solo aparentemente não influenciou a correlação entre os métodos de extração. Contudo, nos solos não cultivados, o teor de P extraído pelos diferentes métodos mostrou-se dependente dos solos

Quadro 6. Teores de P extraído pelo Mehlich-1 (MP), Mehlich-1 com solo moído (MM), resina em esferas (REP), resina em esferas em saquinho (RESP), resina em esferas em saquinho com solo moído (RESM), resina em lâmina (RLP), resina em lâmina com solo moído (RLM) e resina em lâmina com solo moído por bola de vidro (RLB) em amostras dos solos cultivados

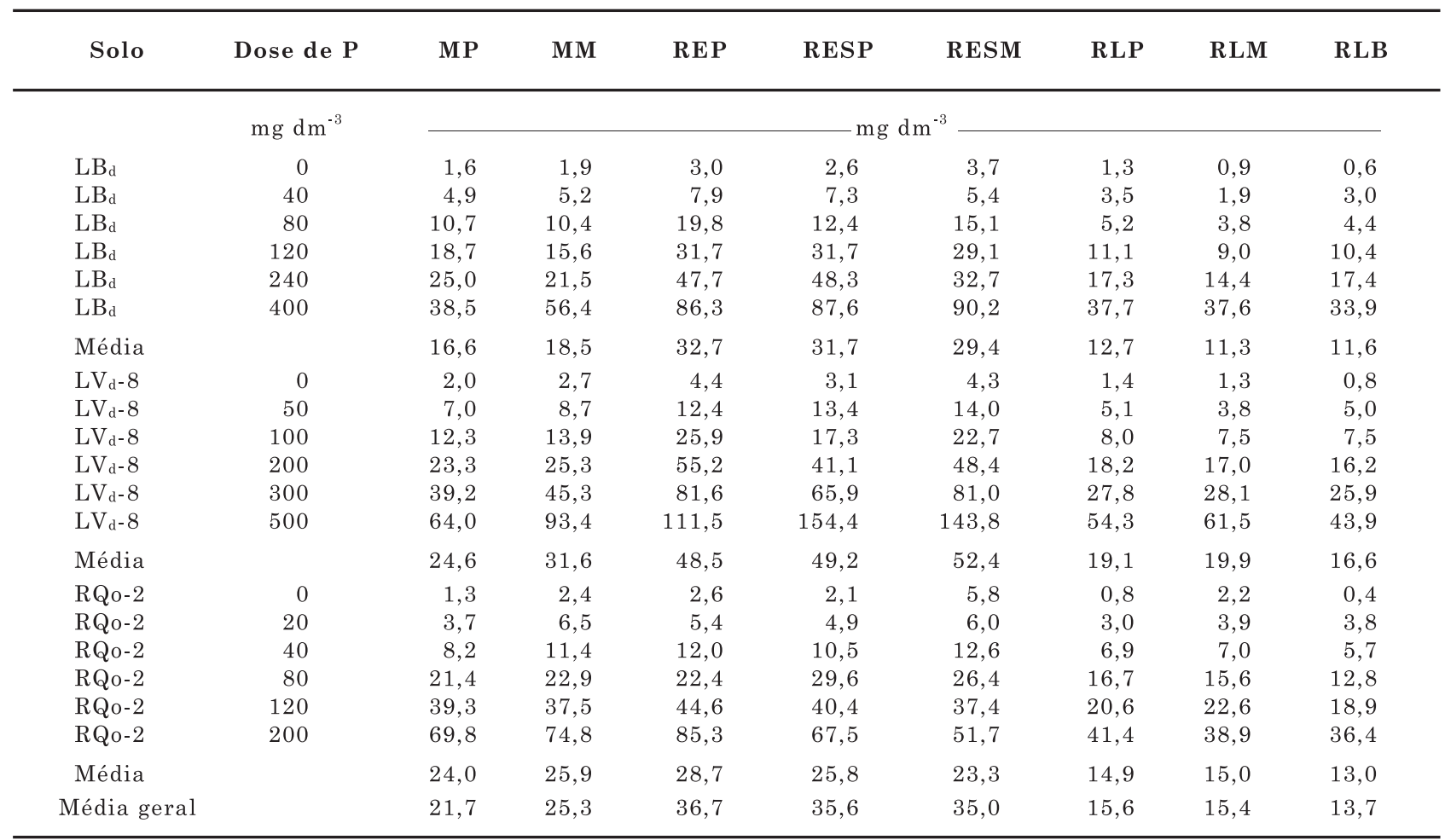


na análise de variância. A capacidade do solo em suprir $\mathrm{P}$ às plantas está relacionada também com características, principalmente, com as relacinadas com o fator capacidade. Solos com maior fator capacidade de $\mathrm{P}$ e com o mesmo valor de P-lábil têm menor concentração de $\mathrm{P}$ em solução, proporcionado menor absorção de P pelas plantas (Novais \& Smyth, 1999).

Para as maiores doses de $\mathrm{P}$, houve maior produção de matéria seca, teor e conteúdo de P na parte aérea das plantas de milho, em todos os solos, (Quadro 7). Em razão do método adotado, no qual as doses de $\mathrm{P}$ foram estabelecidas de acordo com o teor de argila dos solos, a produção de matéria seca da parte aérea, o teor e conteúdo de $\mathrm{P}$ variaram pouco entre os solos. Fonseca et al. (1997), ao adotarem critérios semelhantes para a escolha das doses de P, observaram maiores produções de matéria seca nos solos mais argilosos, que receberam maiores doses de $\mathrm{P}$ em relação aos mais arenosos. Normalmente, o que se observa é o menor acúmulo de $\mathrm{P}$, ou produção de matéria seca, nos solos com maior fator capacidade para a mesma dose de P aplicada (Silva \& Raij, 1996).

A adição das doses de $\mathrm{P}$ ao solo promoveu aumento crescente na produção das plantas e na capacidade dos extratores em extrair esse elemento. Em razão disso, há aumento da capacidade preditiva dos métodos de extração, que é maior que as usualmente encontradas na literatura, compensando a nãoinclusão de uma medida do fator capacidade na interpretação dos resultados do Mehlich-1 (Silva \& Raij, 1996). Contrariando essa idéia, Bonfim et al. (2004), utilizando o mesmo critério para a escolha das doses de $\mathrm{P}$, concluíram que os níveis críticos de $\mathrm{P}$ nos solos e nas plantas foram influenciados pelo fator capacidade, encontrando menores níveis críticos nos solos com maior fator capacidade, como de fato esperado (Novais \& Smyth, 1999).

A produção de matéria seca, o teor e o conteúdo de $\mathrm{P}$ correlacionaram-se significativamente com os teores de P extraído para todos os métodos (Quadro 8). Por essa análise, esses métodos foram eficientes em explicar a resposta da planta, podendo ser utilizados como extratores do"P disponível". Em trabalho semelhante, Bissani et al. (2002) também constataram alta correlação entre o $\mathrm{P}$ extraído pelo Mehlich-1, resina em esfera e em lâmina com a produção e teor de $\mathrm{P}$ em plantas de trigo. Todavia, os métodos cujas amostras de solo receberam moagem (MM, RESM e RLM), embora tenham apresentado correlação significativa com a produção vegetal, apresentaram menor capacidade preditiva que os métodos que não realizaram a moagem das amostras de solo.

Esse efeito foi marcante para a resina em esferas acondicionadas em saquinho, sugerindo que a moagem aumenta a extração de formas não-lábeis de P. Outro complicador em relação à moagem das amostras de solo é que ela deve ser completamente moída, não deixando sobras, para não reduzir ainda mais a eficiência do extrator na determinação do $\mathrm{P}$ disponível. Logo, não pode haver segregação (descarte) de partículas de maior tamanho como areias e agregados de difícil moagem, comum nos solos mais oxídicos, levando à superestimação do $\mathrm{P}$ disponível. Corroborando esta afirmativa, (Maguire et al., 2002) avaliaram a influência de diferentes frações de agregados (2-52, 53-150 e 151-2.000 ㅆm) no P-solução

\section{Quadro 7. Produção de matéria seca, teor e conteúdo de P na parte aérea das plantas de milho}

\begin{tabular}{|c|c|c|c|c|}
\hline Solo & Dose de $P$ & Matéria Seca & Teor de $P$ & Conteúdo de $P$ \\
\hline & $\mathrm{mg} \mathrm{dm^{-3 }}$ & g/vaso & $\mathrm{g} \mathrm{kg}^{-1}$ & $\mathrm{mg} / \mathrm{vaso}$ \\
\hline $\mathrm{LB}_{\mathrm{d}}$ & 0 & 2,19 & 0,74 & 0,163 \\
\hline $\mathrm{LB}_{\mathrm{d}}$ & 40 & 2,61 & 0,93 & 0,242 \\
\hline $\mathrm{LB}_{\mathrm{d}}$ & 80 & 3,62 & 1,06 & 0,383 \\
\hline $\mathrm{LB}_{\mathrm{d}}$ & 120 & 5,27 & 1,23 & 0,646 \\
\hline $\mathrm{LB}_{\mathrm{d}}$ & 240 & 6,51 & 1,40 & 0,914 \\
\hline $\mathrm{LB}_{\mathrm{d}}$ & 400 & 7,02 & 1,86 & 1,309 \\
\hline $\mathrm{LV}_{\mathrm{d}}-8$ & 0 & 1,83 & 0,83 & 0,153 \\
\hline $\mathrm{LV}_{\mathrm{d}}-8$ & 50 & 2,72 & 0,92 & 0,250 \\
\hline $\mathrm{LV}_{\mathrm{d}}-8$ & 100 & 3,85 & 1,14 & 0,437 \\
\hline $\mathrm{LV}_{d}-8$ & 200 & 5,39 & 1,34 & 0,720 \\
\hline $\mathrm{LV}_{\mathrm{d}}-8$ & 300 & 6,57 & 1,64 & 1,075 \\
\hline$L V_{d}-8$ & 500 & 7,74 & 2,50 & 1,936 \\
\hline NQo-2 & 0 & 1,75 & 0,84 & 0,147 \\
\hline NQo-2 & 20 & 2,32 & 0,98 & 0,227 \\
\hline NQo-2 & 40 & 3,21 & 1,03 & 0,330 \\
\hline NQo-2 & 80 & 5,32 & 1,16 & 0,619 \\
\hline NQo-2 & 120 & 5,89 & 1,50 & 0,883 \\
\hline NQo-2 & 200 & 7,78 & 2,40 & 1,870 \\
\hline
\end{tabular}


Quadro 8. Coeficiente de correlação linear simples entre os valores médios de $\mathbf{P}$ extraído pelo Mehlich-1 (MP), Mehlich-1 com solo moído $(M M)$, resina em esferas (REP), resina em esferas em saquinho (RESP), resina em esferas em saquinho com solo moído (RESM), resina em lâmina (RLP), resina em lâmina com solo moído (RLM) e resina em lâmina com solo moído por bola de vidro (RLB) com a produção de matéria seca e teor e conteúdo de $\mathrm{P}$ em amostras dos solos cultivados

\begin{tabular}{llll}
\hline & Matéria seca & $\begin{array}{c}\text { Teor } \\
\text { de P }\end{array}$ & $\begin{array}{c}\text { Conteúdo } \\
\text { de P }\end{array}$ \\
\hline MP & $0,93^{* * *}$ & $0,98^{* * *}$ & $0,98 * * *$ \\
MM & $0,88^{* * *}$ & $0,98^{* * *}$ & $0,99 * * *$ \\
REP & $0,93 * * *$ & $0,96 * * *$ & $0,95 * * *$ \\
RESP & $0,87 * * *$ & $0,93 * * *$ & $0,93 * * *$ \\
RESM & $0,82 * * *$ & $0,88^{* * *}$ & $0,88^{* * *}$ \\
RLP & $0,91 * * *$ & $0,98^{* * *}$ & $0,98 * * *$ \\
RLM & $0,87 * * *$ & $0,96 * * *$ & $0,97 * * *$ \\
RLB & $0,93 * * *$ & $0,99 * * *$ & $0,98 * * *$ \\
Matéria seca & & $0,91 * * *$ & $0,93 * * *$ \\
\hline
\end{tabular}

***: Significativo pelo teste $\mathrm{F}$ a $0,1 \%$.

(fator intensidade) e verificaram maiores teores de Presina e maior fator capacidade nos agregados de menor tamanho. Similarmente, a mineralização e a utilização de formas orgânicas de $\mathrm{P}$ por gramíneas de clima temperado correlacionam positivamente com o tamanho dos agregados (McDowell et al., 2006).

Um método promissor para as análises em laboratórios de rotina é a resina em lâmina, em razão da elevada correlação do P extraído por esse método com a produção vegetal e por este ser menos trabalhoso que os métodos que utilizam a resina em forma de esferas. A resina em lâmina foi utilizada com êxito para medir o "P disponível" por outros autores (Parfitt et al., 1994; Myers et al., 2005). Para análise de P, Cooperband \& Logan (1994) testaram a resina em lâmina, considerando-a eficiente na avaliação do $\mathrm{P}$ em soluções puras de laboratório e do P-lábil em solos. Bissani et al. (2002) testaram o Mehlich-1, a resina em esferas e em lâmina em 20 solos do Rio Grande do Sul e encontraram resultados semelhantes entre estes três métodos e a resposta das plantas. O modo de ação da resina em lâmina é o mesmo da resina em esferas, o que permite sua indicação para solos com teor elevado de P-Ca.

\section{CONCLUSÕES}

1. A moagem das amostras de solo não aumentou a extração de $\mathrm{P}$ pelo Mehlich-1 e pela resina em lâmina, nas amostras dos solos não adubados e cultivados. No entanto, para a resina em esferas, a moagem das amostras aumentou a extração de $\mathrm{P}$, sendo esse efeito mais marcante nos solos não cultivados e que não receberam fertilizante fosfatado.

2. Todos os métodos correlacionaram bem com a resposta vegetal. Todavia, a moagem das amostras de solo reduziu a sensibilidade de todos os métodos, sobretudo da resina em esferas.

3. A resina em lâmina mostrou-se eficiente para determinação do $\mathrm{P}$ disponível, não tendo os inconvenientes da resina em esferas e do Mehlich-1 revelando ser método promissor para uso em laboratórios de rotina.

\section{LITERATURA CITADA}

ALVAREZ V., V.H. \& FONSECA. D.M. Definição de doses para determinação da capacidade máxima de adsorção de fosfatos e para ensaios em casa de vegetação. R. Bras. Ci. Solo, 14:49-55, 1990

ALVAREZ V., V.H.; NOVAIS, R.F.; DIAS, L.E. \& OLIVEIRA, J.A. Determinação e uso do fósforo remanescente. B. Inf. SBCS, 25:27-32, 2000.

BISSANI, C.A.; TEDESCO, M.J.; CAMARGO, F.A.O.; MIOLA, L. \& GIANELLO, C. Anion-exchange resins and iron oxide-impregnated filter paper as plant available phosphorus indicators in soil. Comm. Soil Sci. Plant Anal., 33:1119-1130, 2002.

BONFIM, E.M.S.; FREIRE, F.J.; SANTOS, M.V.F.; SILVA, T.J.A. \& FREIRE, M.B.G.S. Níveis críticos de fósforo para brachiaria brizantha e suas relações com características físicas e químicas em solos de Pernambuco. R. Bras. Ci. Solo, 28:281-288, 2004.

COMISSÃO DE FERTILIDADE DO SOLO DO ESTADO DE MINAS GERAIS - CFSEMG. Recomendações para o uso de corretivos e fertilizantes em Minas Gerais $\left(5^{\mathrm{a}}\right.$ aproximação) Viçosa, MG, 1999. 359p.

COOPERBAND, L.R. \& LOGAN, T.J. Measuring in situ changes in labile soil phosphorus with anion-exchange membranes. Soil. Sci. Soc. Am. J., 58:105-114, 1994.

DEFELIPO, B.V. \& RIBEIRO, A.C. Análise química do solo. 2.ed. Viçosa, MG, Universidade Federal de Viçosa, 1997. $26 \mathrm{p}$.

FERNANDES, M.L.V. \& WARREN, G.P. Comparison of resin beads and resin membranes for extracting soil phosphate. Nutr. Cycling Agroecossyst., 44:1-8,1995.

FIXEN, P.E. \& GROVE, J.H. Testing soils for phosphorus. In: WESTERMAN, T. L., ed. Soil testing and plants analysis. 3.ed. Madison, Soil Science Society of America, 1990. p.141-180.

FONSECA, D.M.; GOMIDE, J.A.; ALVAREZ V., V.H. \& NOVAIS, R.F. Fatores que infuenciam os níveis críticos de fósforo para o estabelecimento de gramíneas forrageiras: II. Em campo. R. Bras. Ci. Solo, 21:35-40, 1997. 
GUNARY, D. \& SUTTON, C.D. Soil factors affecting plant uptake of phosphate. J. Soil Sci., 18:167-173, 1967.

HOSSEINPUR, A.R. \& GHANEE, A.H. Comparison of iron oxide-impregnated paper strips with other extractants in determining available soil phosphorus. Comm. Soil Sci. Plant Anal., 37:889-897, 2006.

HOUBA, V.G.H.; CHARDON, W.J. \& POESE, K. Influence of grinding of soil apparent chemical composition. Comm. Soil Sci. Plant Anal., 24:1591-1602, 1993.

LEE, J.H. \& DOOLITTLE, J.J. A proposed method for determining soil phosphorus desorption quantity intensity relationships using anion exchange membrane disks. Comm. Soil. Sci. Plant Anal., 33:1941-1958, 2002.

MAGUIRE, R.O.; EDWARDS, A.C.; SIMS, J.T.; KLEINMAN, P.J.A. \& SHARPLEY, A.N. Effect of mixing aggregates on the phosphorus concentration in surface waters. J. Environ. Qual., 31:1294-1299, 2002

McDOWELL, R.C.; SCOTT, J.T. \& CONDRON, L.M. Influence of aggregate size on phosphorus loss and ryegrass yield in a soil cultivated intermittently. Soil Use Manag., 22:224226,2006

MOREIRA, A. \& MALAVOLTA, E. Fontes, doses e extratores de fósforo em alfafa e centrosema. Pesq. Agropec. Bras., 36:1519-1527, 2001.

MURPHY, J. \& RILEY, J.P. A modified single solution method for determination of phosphate in natural waters. Anal Chim. Acta, 27:31-36, 1962.

MYERS, R.G.; SHARPLEY, A.N.; THIEN, S.J. \& PIERYNSKI, G.M. Íon-sink extraction methods applied on 24 soils from the continental USA. Soil Sci. Soc. Am. J., 69:511521,2005 .

NOVAIS, R.F. \& SMYTH, T.J. Fósforo em solo e planta em condições tropicais. Viçosa, MG, Universidade Federal de Viçosa, 1999. 399p.

PARFITT, R.L.; TATE, K.R. \& McKERCHER, R.B. Measurement of phosphorus mineralisation using an anion exchange membrane. Comm. Soil Sci. Plant Anal., 25:3209-3219, 1994
RAIJ, B.van; QUAGGIO, J.A.; CANTARELLA, H.; FERREIRA, M.E.; LOPES, A.S. \& BATAGLIA, O.C. Análise química do solo para fins de fertilidade. Campinas, Fundação Cargill, 1987. 170p.

RUIZ, H.A. Incremento da exatidão da análise granulométrica do solo por meio da coleta da suspensão. R. Bras. Ci. Solo, 29:297-300, 2005

RUIZ, H.A.; FERREIRA, G.B. \& PEREIRA, J.B. Estimativa da capacidade de campo de Latossolos e Neossolos Quartzarênicos pela determinação do equivalente de umidade. R. Bras. Ci. Solo, 27:389-393, 2003.

SAGGAR, S.; HEDLEY, M.J. \& WHITE, R.E. A simplified resin membrane technique for extracting phosphorus from soils. Nutr. Cycling Agroecossyst., 24: 173-180, 1990.

SIBBESEN, E. An investigation of the anion-exchange resin method for phosphate extraction. Plant Soil, 50:305-321, 1978.

SILVA, F.C. \& RAIJ, B.van Avaliação da disponibilidade de fósforo, por diversos extratores, em amostras de solos cultivados com cana-de-açúcar. R. Bras. Ci. Solo, 20:8390,1996 .

SILVA, F.C. \& RAIJ, B.van. Disponibilidade de fósforo em solos avaliada por diferentes extratores. Pesq. Agropec. Bras., 34:267-288, 1999.

TAKAHASHI, S. Influence of soil particle size and grinding on Bray-2 extractable phosphorus. Comm. Soil Sci. Plant Anal., 27:2829-2835, 1996.

WANG, X.; YOST, R.S. \& LINQUIST, B.A. Soil aggregate size affects phosphorus desorption from highly weathered soils and plant growth. Soil Sci. Soc. Am. J., 65:139-146, 2001.

YOSHIDA, M. Effects of dry grinding on P retention properties of Andosols. Soil Sci. Plant. Nutr., 38:637-645, 1992.

ZUNINO, H.; AGUILERA, M. \& PEIRANO, P. A modified resin exchange method for measurement of available phosphate in soils derived from volcanic ash. Soil Sci., 114:404-405,1972. 